\title{
ĐĂC ĐIỂM LÂM SÀNG UNG THƯ ỐNG TIÊU HÓA KHÔNG THUộC BIỂU MÔ ĐƯợC PHẪU THUÂT TẠI BỆNH VIỆN HỮU NGHI VIẸTT ĐỨC TRONG 10 NĂM
}

\section{TÓM TẮT}

Mục tiêu: mô tả các hình thái lâm sàng của ung thư ổng tiêu hóa (ÔTH) không thuộc biểu mô. Phương pháp: Nghiên cứu mô tả hồi cứu. Kết quả: U GIST và u lympho ác tính chiểm tî lệ cao nhất $(70,6 \%$ và $26 \%)$, da dày và ruột non là 2 vị trí tổn thương thường gặp nhất, u GIST gặp nhiều nhất ở da dày $(56,7 \%)$, u lympho lại chủ yếu tại dạ dày $(38,8 \%)$ và ruột non $(27,6 \%)$. Đau bụng là dâu hiệu thường gặp nhất, thiếu máu hay gặp u GIST và lympho (chủ yểu tiêu hóa cao), tắc ruột và bán tắc ruột hay gặp tại ruột non và manh tràng. Viêm phúc mạc thướng do thửng hoăc hoại tử ruột, chủ yếu ở ruột non, với u lympho và u GIST. Kết luận: u không thuộc biểu mô có nhữ̛ng biến chứng nặng mang tính chất cấp cứu có thể dẫn đến tử vong (như xuất huyết tiêu hóa, thủng ruột, tắc ruột, lồng ruột...), do vậy việc hiểu được rỗ đặc điểm lâm sàng và vấn đề cân thiết phải chẩn đoán xác định u mô đệm, u lympho và các u trung mô khác của ÔTH là rất quan trọng để có phương pháp điều trị phù hợp và hiệu quả cho bệnh nhân.

Tì̛ khóa: U không thuộc biểu mô ống tiêu hóa, đặc điểm lâm sàng, vị trí tổn thương

\section{SUMMARY \\ CLINICAL CHARACTERISTICS OF NON- EPITHELIAL CANCER OF GASTROINTESTINAL TRACT OPERATED AT VIET DUC UNIVERSITY HOSPITAL IN 10 YEAR}

Objective: Describe the clinical of non-epithelial cancer of gastrointestinal tract (GI). Methods: retrospective study. Results: GIST and malignant lymphoma had the highest prevalence $(70.6 \%$ and $26 \%$, stomach and small intestine were the two most common lesions, GIST tumors were most common in the stomach $(56.7 \%)$, lymphoma mainly in the stomach (38.8\%) and small intestine (27.6\%). Abdominal pain is the most common symptom, anemia is common with GIST and lymphoma (mainly upper GI), obstruction is common in the small intestine and cecum. Peritonitis is usually caused by perforation or necrosis of the intestine, mainly in the small intestine, with lymphoma and GIST tumors. Conclusion: non-epithelial tumors have serious complications of an emergency that can lead to death (such as gastrointestinal bleeding, perforation, obstruction, intussusception...), therefore, it is

${ }^{1}$ Bệnh viện Hữu nghi Việt Đức

Chịu trách nhiệm chính: Phạm Gia Anh

Email: phamgiaanh@gmail.com

Ngày nhận bài: 16.11.2020

Ngày phản biện khoa học: 4.01.2021

Ngày duyệt bài: 15.01.2021

\section{Phạm Gia Anh', Trịnh Hồng Sơn ${ }^{1}$}

important to understand the clinical features and the need for a definitive diagnosis of GIST, lymphoma and other mesenchymal tumors of the GI tract. There are appropriate and effective treatments for the patient.

Keywords: non-epithelial gastrointestinal tract tumors, clinical characteristics, tumor location

\section{I. ĐĂT VẤN ĐỀ}

Ung thư ống tiêu hóa (ÔTH) không thuộc biểu mô bao gồm nhóm u trung mô (Digestive Mesenchymal Tumors) và u lympho của ÔTH, chiếm tỉ lệ dưới $5 \%$ toàn bộ ung thư của ÔTH, có hơn 10 loại khác nhau bao gồm nhóm chiếm tỉ lệ ít hơn có hình ảnh mô bệnh học và tiêu chuẩn chẩn đoán giống u mô mềm ở các cơ quan khác như u mõ̃, u cơ trơn, u vỏ bao thần kinh, u mạch máu, u cơ vân... và nhóm khác chiếm phần lớn không đồng nhất gọi là u mô đệm ống tiêu hoá hay u mô đệm dạ dày ruột (GIST - GastroIntestinal Stromal Tumors) và u lympho [1], [2]. Trên thế giới và tại Việt Nam cũng đã có các công trình nghiên cứu về u ÔTH không thuộc biểu mô, tuy nhiên các tác giả thường nghiên cứu một loại tổn thương trên một hoặc nhiều tạng mà chưa có nghiên cứu nào một cách tổng thể của các loại u không thuộc biểu mô của toàn bộ ÔTH. Mặc dù chiếm tỷ lệ thấp hơn nhiều so ung thư biểu mô, nhưng các u này cũng có những biến chứng nặng mang tính chất cấp cứu có thể dẫn đến tử vong (như xuất huyết tiêu hóa, thủng ruột, tắc ruột, lồng ruột...), do vậy việc hiểu được rõ đặc điểm lâm sàng và vấn đề cần thiết phải chẩn đoán xác định u mô đệm, u lympho và các u trung mô khác của ÔTH là rất quan trọng để có phương pháp điều trị phù hợp và hiệu quả cho bệnh nhân. Chính vì vậy chúng tôi thực hiện nghiên cứu này nhằm mục tiêu: "Mô tả các đặc điểm lâm sàng của ung thư ống tiêu hóa không thuộc biểu mô".

II. ĐỐI TƯợNG VÀ PHƯƠNG PHÁP NGHIÊN CỨU

2.1. Địa điểm, thời gian nghiên cứu: Bệnh viện Hữu nghị Việt Đức trong thời gian 10 nămm từ $1 / 2009$ đến 4/2019.

2.2. Đối tượng nghiên cứu: Những bệnh nhân có khối u mõ ác tính tại ống tiêu hóa được chẩn đoán xác định bằng giải phẫu bệnh, đã phẫu thuật cấp cứu hoặc mố phiên tại Bệnh viện hữu nghị Việt Đức. 
2.3. Phương pháp nghiên cứu

2.3.1. Thiết kế nghiên cứu: Nghiên cứu hồi cứu theo phương pháp mô tả

2.3.2. Cỡ mấu: Tất cả các các bênh nhân đủ tiêu chuẩn nghiên cứu trong thời gian 10 năm từ 1/2009 đến 4/2019

\subsubsection{Phương pháp thu thập số lieệu}

Bước 1: Lấy toàn bộ kết quả giải phẫu bệnh tại khoa giải phẫu bệnh trong 10 năm từ 1/2009 đến 4/2019

Bước 2: Trong các kết quả này, lọc ra những chẩn đoán u mõ ác tính của thực quản, dạ dày, tá tràng, ruột non, đại tràng, trực tràng và hậu môn.

Bước 3: - Từ kết quả thu được ở bước 2, lập danh sách tên, tuổi, chẩn đoán lâm sàng, khoa phò̀ng gửi bệnh phẩm và ngày đọc tiêu bản giải phẫu bệnh.

- Từ đó tra được ngày ra vào viện của từng bệnh nhân để tìm hồ sơ bệnh án.

- Kiểm tra hồ sơ đầy đủ mới lấy vào số liệu.

2.3.4. Tiêu chuẩn lựa chọn bệnh nhân: Mỗi bệnh nhân được lựa chọn vào nghiên cứu có đầy đủ các tiêu chuẩn sau:
- Kết quả giải phẫu bệnh chẩn đoán xác định là u mõ ác tính ống tiêu hóa

- Cả hai giới nam và nữ, mọi lứa tuổi.

- Được điều trị phẫu thuật.

- Có đầy đủ hồ sơ bệnh án với lâm sàng và kết quả cận lâm sàng, biên bản phẫu thuật, giấy kết quả giải phẫu bệnh.

\subsection{Chỉ tiêu nghiên cứu}

- Chỉ tiêu chung: Tuổi, giới, tiền sử nội ngoại khoa, lý do vào viện, tính chất mổ (phiên, cấp cứu), phát hiện tình cờ hay không.

- Triệu chứng lâm sàng: dấu hiệu ung thư, sốt, thiếu máu, đau bụng, sờ thấy u bụng, bán hay tắc ruột, viêm phúc mạc, xuất huyết tiêu hóa.

2.5. Phương pháp xử lý số liệu: Phần mềm SPSS 22.0

\section{KẾT QUẢ NGHIÊN CỨU}

Nghiên cứu của chúng tôi tiến hành trên 557 bệnh nhân với tuổi trung bình là $57,1 \pm 14,7$; tuổi cao nhất là 88 tuổi và thấp nhất là 3 tuổi. Đối tượng tham gia nghiên cứu chủ yếu trên 50 tuổi chiếm 71,6\%. Tỉ lệ nam/nữ = 1,13.

\subsection{Tỉ lệ các loại ung thư không biểu mô tại ống tiêu hóa}

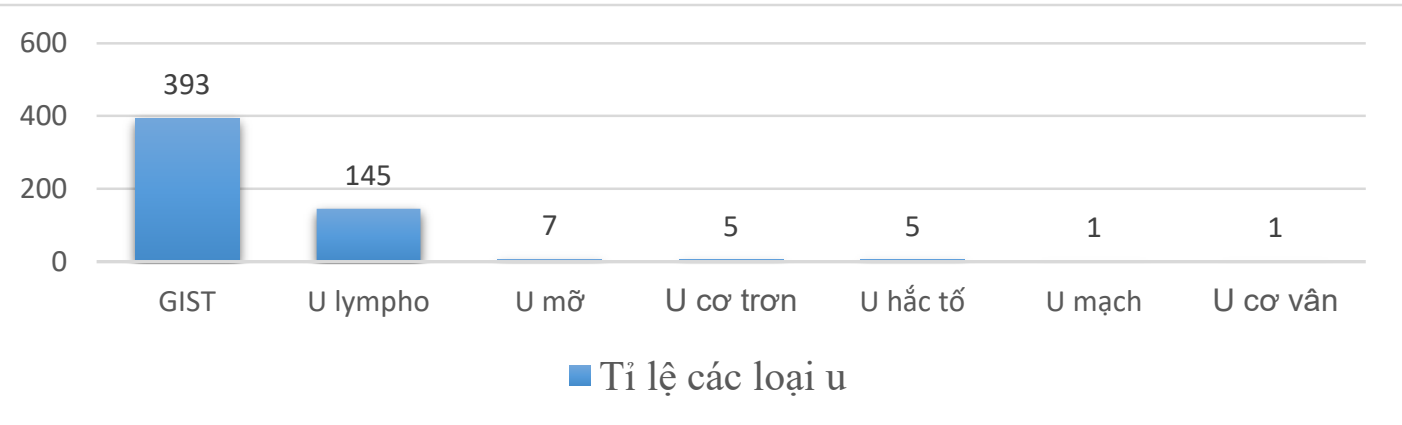

Biểu đồ 3.1. Tỉ lệ các loại ung thư không biểu mô tại ống tiêu hóa

Nhận xét: - Nhiều nhất là u GIST (70,6\%), u lympho ác tính (26\%).

- Không có u vỏ bao thần kinh ác tính, u Kaposi, u hạt, u cuộn mạch và ung thư tế bào sáng.

\subsection{Vị trí ống tiêu hóa có tổn thương}

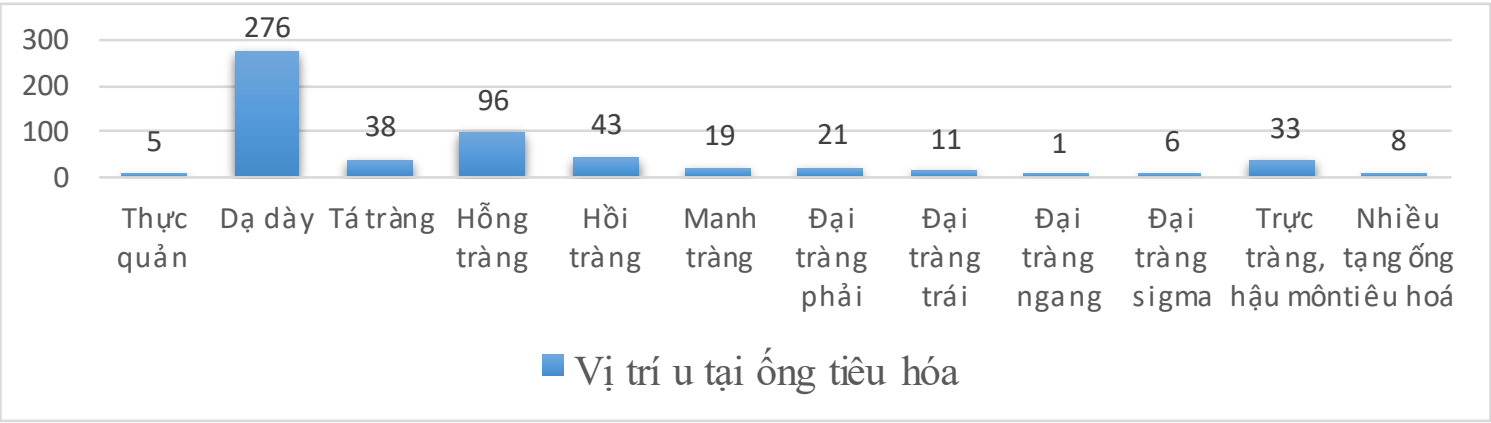

Biểu đồ 3.2. Vị trí ống tiêu hóa có tổn thương

Nhận xét. - Gặp nhiều nhất ở dạ dày và ruột non (hỗng tràng, hồi tràng)

- Rất ít tổn thương ở thực quản 


\subsection{Liên quan triệu chứng, hội chứng lâm sàng và vị trí ống tiêu hóa có tổn thương} Bảng 3.1. Triệu chứng, hội chứng lâm sàng và vị trí tổn thương

\begin{tabular}{|c|c|c|c|c|c|c|c|c|c|}
\hline $\begin{array}{l}\text { Vị trí tổn } \\
\text { thương }\end{array}$ & $\begin{array}{c}\text { Triệu } \\
\text { chứng K } \\
\text { n (\%) }\end{array}$ & $\begin{array}{c}\text { Sốt } \\
\text { n (\%) }\end{array}$ & $\begin{array}{l}\text { Thiếu } \\
\text { máu } \\
\text { n (\%) }\end{array}$ & $\begin{array}{c}\text { Đau } \\
\text { bụng } \\
\text { n (\%) }\end{array}$ & $\begin{array}{c}\text { Bán tắd } \\
\text { ruột } \\
\text { n (\%) }\end{array}$ & $\begin{array}{c}\text { Tắc } \\
\text { ruột } \\
\text { n (\%) }\end{array}$ & $\begin{array}{l}\text { XHTH } \\
\text { n (\%) }\end{array}$ & $\begin{array}{l}\text { VFM } \\
\text { n (\%) }\end{array}$ & $\begin{array}{l}\text { Khối u } \\
\text { bưng } \\
\text { n (\%) }\end{array}$ \\
\hline Thức quản & $2(1,1)$ & $0(0)$ & $2(1,3)$ & $0(0)$ & $0(0)$ & $0(0)$ & $0(0)$ & $0(0)$ & $0(0)$ \\
\hline Dạ dày & $91(51,4)$ & $8(40,0)$ & $65(42,5)$ & $192(49,2)$ & $0(0)$ & $0(0)$ & $59(47,6)$ & $1(5,9)$ & $49(45,3)$ \\
\hline Tá tràng & $10(5,7)$ & $0(0)$ & $12(7,8)$ & $28(7,2)$ & $0(0$ & $0(0)$ & $9(7,3)$ & $0(0)$ & $5(4,6)$ \\
\hline Hống tr & $32(18,1)$ & $5(25,0)$ & $38(24,8)$ & $71(18,2)$ & $4(25)$ & $7(43,8)$ & $20(16,1)$ & $8(47)$ & $25(23,1)$ \\
\hline & $13(7,3)$ & & $11(7,2)$ & $33(8,5)$ & $6(37,5)$ & $5(31,3)$ & & $5(29,4)$ & $14(12,9)$ \\
\hline $\mathrm{Ma}$ & $(2,2)$ & & $6(3,9)$ & $18(4,6)$ & $2(12,5)$ & $3(18,8)$ & $5(4,0)$ & $3(17,7)$ & $2(1,9)$ \\
\hline Đaai tr & $7(4,0)$ & $2(10,0)$ & $4(2,6)$ & $18(4,6)$ & $2(12,5)$ & $0(0)$ & $5,7)$ & $0(0)$ & $6(5,6)$ \\
\hline Đại tràng trái & $2(1,1)$ & $0(0)$ & $2(1,3)$ & $9(2,3)$ & $0(0)$ & $0(0)$ & $1(0,8)$ & $0(0$ & $3(2,8)$ \\
\hline Đai tràng ngang & $0(0)$ & $0(0)$ & $0(0)$ & $1(0,3)$ & $0(0)$ & $0(0)$ & $0(0)$ & $0(0)$ & $0(0)$ \\
\hline Đại t & $1(0,6)$ & $0(0)$ & $1(0,7)$ & $4(1,0)$ & $0(0)$ & $0(0)$ & $0(0)$ & $0(0)$ & $2(1,9)$ \\
\hline $\begin{array}{l}\text { Trực tràng, } \\
\text { hậu môn }\end{array}$ & $10(5,7)$ & $1(5,0)$ & $10(6,5)$ & $10(2,6)$ & $2(12,5)$ & $0(0)$ & $15(12,1)$ & $0(0)$ & $0(0)$ \\
\hline Nhiều tạng & & & $2(1,3)$ & $6(1,5)$ & $0(0)$ & $1(6,2)$ & & & $2(1,9)$ \\
\hline Tổng & $\begin{array}{c}177 \\
(100)\end{array}$ & $\begin{array}{c}20 \\
(100)\end{array}$ & $\begin{array}{l}153 \\
(100)\end{array}$ & $\begin{array}{c}390 \\
(100)\end{array}$ & $\begin{array}{c}16 \\
(100)\end{array}$ & $\begin{array}{c}16 \\
(100)\end{array}$ & $\begin{array}{c}124 \\
(100)\end{array}$ & $\begin{array}{c}17 \\
(100)\end{array}$ & $\begin{array}{l}108 \\
(100)\end{array}$ \\
\hline
\end{tabular}
dày và hỗng tràng)

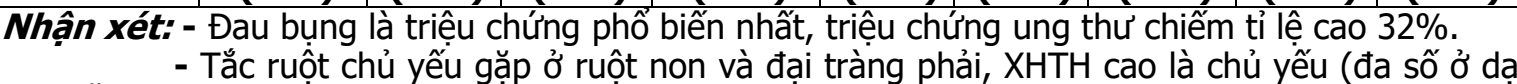
- VFM chủ yếu do tổn thương tại ruột non.

3.4. Liên quan triệu chứng và hội chứng lẩm sàng của các loại u

Bảng 3.2. Triệu chứng, hội chứng lâm sàng cuả các loại u

\begin{tabular}{|c|c|c|c|c|c|c|c|c|c|}
\hline $\begin{array}{l}\text { Loại tổn } \\
\text { thương }\end{array}$ & $\begin{array}{c}\text { Triệu } \\
\text { chứng K } \\
\text { n (\%) }\end{array}$ & $\begin{array}{c}\text { Sốt } \\
\text { n (\%) }\end{array}$ & $\begin{array}{l}\text { Thiếu } \\
\text { máu } \\
\text { n (\%) }\end{array}$ & & $\begin{array}{c}\text { Bán tắc } \\
\text { ruột } \\
\text { n (\%) }\end{array}$ & $\begin{array}{c}\text { Tắc } \\
\text { ruột } \\
\text { n (\%) }\end{array}$ & & & $\begin{array}{l}\text { Khối u } \\
\text { bụng } \\
\text { n (\%) }\end{array}$ \\
\hline & $0(0)$ & $0(0)$ & $0(0)$ & $2(0,5)$ & $0(0)$ & $0(0)$ & $0(0)$ & $0(0)$ & $1(0,9)$ \\
\hline & $3(24,3)$ & & $(23,5)$ & & $10(62,5)$ & $10(62,5)$ & & & $29(26,9)$ \\
\hline & $3(1,7)$ & & $1(0,7)$ & & $0(0)$ & $0(0)$ & & & $2(1,9)$ \\
\hline & & & & & & & & & \\
\hline & & & & & & I & & & \\
\hline & & & & & & $0)$ & & & $0(0)$ \\
\hline & $31(74,0)$ & $11(55,0)$ & $114(74,5)$ & & $6(37,5)$ & $6(37,5)$ & $93(7$ & $5(29,0)$ & $75(69,4)$ \\
\hline & $\begin{array}{c}177 \\
(100)\end{array}$ & & $\begin{array}{c}153 \\
(100)\end{array}$ & & $\begin{array}{c}16 \\
(100)\end{array}$ & $\begin{array}{c}16 \\
(100)\end{array}$ & $\begin{array}{c}124 \\
(100)\end{array}$ & $\begin{array}{c}17 \\
(100)\end{array}$ & $\begin{array}{c}108 \\
(100)\end{array}$ \\
\hline
\end{tabular}

Nhận xét: - Đau bụng và có triệu chứng ung thư là 2 dấu hiệu phố biến nhất.

- XHTH gặp nhiều ở u lympho và u GIST, trong đó $4 / 5$ u hắc tố có dấu hiệu này.

- VFM do thủng hoă̆c hoại tử ruột gặp nhiều ở u lympho.

- Tắc ruột và bán tắc ruột chỉ gặp ở u GIST và u lympho.

\section{BÀN LUÂN}

4.1. Tỉ lệ của các loại ung thư không biểu mô của ôTH và vị trí của u. Trong 557 bệnh nhân ung thư không biểu mô của toàn bộ ÔTH trong nghiên cứu này, u GIST và u lympho ác tính chiểm tỉ lệ cao nhất tương ứng với 70,6\% và $26 \%$, đây vẫn là các loại ung thư phần mềm (của các tạng trong ổ bụng và ngực) phổ biến thường gặp nhất như trong phân loại mới nhất lần thứ 8 của AJCC [3]. Một số loại tổn thương hiếm gặp khác bao gồm u mõ ác tính $(1,3 \%)$, u cơ trơn ác tính và hắc tố ác tính (0,9\%), u mach máu ác tính và u cơ vân ác tính có tỉ lệ thấp nhất là $0,2 \%$, không có ca nào là u tế bào hạt, u cuộn mạch, u Kaposi hay u tế bào sáng.

Vị trí tổn thương của các loại ung thư không biểu mô, tại dạ dày là chiếm tỉ lệ cao nhất $(49,6 \%)$ so với các vị trí khác của ống tiêu hóa, tiếp đến là hỗng tràng $(17,2 \%)$, hồi tràng $(7,7 \%)$, tá tràng $(6,8 \%)$, ít gặp hơn theo thứ tự ở hậu môn trực tràng $(5,9 \%)$, đại tràng phải $(3,8 \%)$, manh tràng $(3,4 \%)$, đại tràng trái $(2 \%)$, 
thực quản $(0,9)$ và đại tràng ngang là $0,2 \%$. Như vậy dạ dày và ruột non vẫn là 2 vị trí thường gặp nhất của loại u này tại ÔTH, kết quả này giống với của tác giả Phạm Gia Anh năm 2008 về các loại u ác tính của ÔTH [5]

4.2. Mối liên quan giữa đặc điểm lâm sàng và các loại ung thư không thuộc biểu mô ÔTH.

- Nhóm triệu chứng ung thư (Gầy sút, mệt mỏi, chán ăn) chiếm 31,8\% (177/557 ca), nhiều nhất là ung thư tại dạ dày $(51,4 \%)$ tiếp đến là ruôt non với $25,4 \%$ (32 ca tại hô̂ng tràng và 13 ca tại hồi tràng), đại trực tràng là $13,6 \%$ và tá tràng là $5,7 \%$; tỉ lệ này tướng tự như kết quả của Phạm Gia Anh (2008) [5]. Còn trong các loại u thì GIST chiếm tỉ lệ cao nhất với 131/177 ca (74\%), tiếp đến là u lympho ác tính $24,3 \%$, tiếp đến là u mõ ác tính $(1,7 \%)$, các u cơ vân, cơ trơn, u mạch và u hắc tố ác tính không có triệu chứng này.

- Sốt: chỉ có 20/577 bệnh nhân có dấu hiệu sốt $(3,5 \%)$ trong đó 11 ca GIST (chiếm 2.8\% tổng số u GIST) và 9 ca là u lympho (chiếm $6,2 \%$ tổng số u lympho). Cho thây sốt là dấu hiêu khá thường gặp của bênh cảnh u lympho [7]. Đối với các tạng tổn thươnng, triệu chứng này gặp nhiêu ở dạ dày và hỗng tràng với số bênh nhân tương ứng là 8 và 7 .

- Thiếu máu: 27,4\% (153/557) bênh nhân vào viện có triệu chứng thiếu máu (Hồng cầu dưới 3,5T/I hoặc hematocrit dưới 25\%). Chủ yếu gặp ở u GIST và u lympho với số lượng bệnh nhân tương ứng là 114 (31,4\% bệnh nhân GIST) và 36 (24,8\% bệnh nhân u lympho). Kết quả cũng tương tự với tỉ lệ $21,3 \%$ số bệnh nhân trong nghiên cứu của tác giả Phạm Gia Anh [5] và tác giả Ming C. Là $36 \%$ [8]. Với các loại u khác thì dấu hiệu này gặp $1 / 7$ ca u mõ ác tính, $1 / 5$ ca u hắc tố ác tính, $1 / 1$ ca u mạch ác tính, u cơ vân và cơ trơn không gặp triệu chứng này. Tang tổn thương với triệu chứng này gặp ở tiêu hóa cao, cụ thể ở dạ dày (65 ca) và ruột non (49 $\mathrm{ca}$, trong đó hỗng tràng là chính $38 \mathrm{ca}$ ), tá tràng (12 ca) và trực tràng $10 \mathrm{ca}$.

- Đau bụng: Đa số bệnh nhân vào viện có triệu chứng này, trong nghiên cứu chúng tôi có 390 bệnh nhân (chiếm 70\%), 64\% bệnh nhân GIST, $86 \%$ bệnh nhân u lympho có dấu hiệu này (tác giả Ming C. là $80 \%$ [8]), còn u mõ ác tính thì 6/7 ca. Triệu chứng đau bụng tại các tạng với tổn thương tại dạ dày $49,2 \%$, ruột non $26,7 \%$, đại tràng $12,8 \%$ tá tràng $7,2 \%$, trực tràng là $2,6 \%$. Theo tác giả Nguyến Ngọc Hùng, có 75,8\% các trường hợp u không biểu mô dạ dày có triệu chứng đau bụng, kết quả này cao hơn không nhiều với nghiên cứu của chúng tôi là $69,6 \%(192 / 276)$.

- Bán tắc ruột và tắc ruột: Có 16 trường hợp bán tắc ruột và 16 trường hợp tắc ruột, toàn bộ nằm ở hỗng tràng, hồi tràng và manh tràng, 2 ca bán tắc ở đại tràng phải và 2 ca ở trực tràng, không gặp triệu chứng này với u ở thực quản, dạ dày và tá tràng. Như vậy 2 hội chứng trên chủ yếu xảy ra ở ruột non. Triệu chứng bán tắc ruột và tắc ruột chỉ tập trung vào 2 loại là u lympho $(13,6 \%$ số bệnh nhân u lympho) và GIST $(8,1 \%$ số bệnh nhân u GIST). Kết quả này tương tự với kết quả của Nguyễn Thành Khiêm với $12,3 \%$ triệu chứng tắc ruột ở u lympho.

- Xuất huyết tiêu hóa: Xảy ra tương đối nhiều trong ung thư không biểu mô với 124/557 $(22,3 \%)$, tương tự kết quả của Phạm Gia Anh là 21,3\% [5] trường hợp có nôn máu hoặc ỉa phân đen, chủ yếu gặp với tổn thương tại dạ dày 59 ca $(47,6 \%)$, ruột non 27 ca $(21,8 \%)$ trong đó 20 ca ở hỗng tràng, trực tràng $15 \mathrm{ca}(12,1 \%)$, tá tràng $9 \mathrm{ca}(7,3 \%)$ và đại tràng là $13 \mathrm{ca}(10,5 \%)$. Chủ yếu là tổn thương loại u GIST chiếm $75 \%$ và u lympho $26 \%$, riêng u hắc tố có $4 / 5$ ca có triệu chứng XHTH. Trong 393 ca GIST có 124 ca chiếm $31,6 \%$. Trong 145 ca u lympho trong nghiên cứu chúng tôi có 26 ca XHTH, chiếm 17,9\%, nghiên cứu của Nguyễn Thành Khiêm là 26,5\%.

- Viêm phúc mạc: Chúng tôi gặp 17 ca viêm phúc mạc $(3,1 \%)$, đều do thủng hoặc hoại tử ruột gây nên, tất cả đều được mổ cấp cứu, tổn thương do u lympho chiếm $71 \%$ và u GIST là $29 \%$, các loại u còn lại không có trường hợp nào có triệu chứng này. Vị trí thủng gặp nhiều nhất ở hỗng tràng $8 \mathrm{ca}$, hồi tràng $5 \mathrm{ca}$, manh tràng $3 \mathrm{ca}$ và dạ dày $1 \mathrm{ca}$; không thấy ở tá tràng và đại trực tràng. Triệu chứng viêm phúc mạc trong nghiên cứu của Nguyễn Thành Khiêm chiếm 6,1\% trong tổng số u lympho ÔTH, của chúng tôi là $8,2 \%$, tỉ lệ tùy theo các thông báo lâm sàng nhưng đều dưới $25 \%$.

- Khám thấy khối u bụng: Có 108 bệnh nhân khám thấy dấu hiệu này $(19,3 \%)$, chủ yếu là u GIST $(69,4 \%)$ và u lympho $(26,9 \%), 2$ ca u mõ và 1 ca u cơ vân cá tính. Gặp nhiều với vị trú u tại dạ dày $(45,3 \%)$ và ruột non $(36 \%)$, ít hơn ở đại trực tràng và tá tràng. Trong số các u lympho có dấu hiệu này là $20 \%$, thấp hơn so với nghiên cứu của Nguyễn Thành Khiêm là 34,7\%. Trong nghiên cứu u dạ dày của Nguyễn Ngọc Hùng tỉ lệ này là $58,6 \%$.

- Lý do vào viện: Chủ yếu bệnh nhân vào viện vì lý do đau bụng (69\%), tiếp đến là do xuất huyết tiêu hóa $(17,4 \%)$ và sờ thây khối u 
bụng (7\%). Riêng u tại thực quản thì triệu chứng chủ yếu là nuốt nghẹn (80\%). Có 37 trường hợp phát hiện tình cờ khám định kỳ hoặc đi khám bênh ở tạng khác phát hiện ra khối u ÔTH. Các triêu chứng như sốt, thiếu máu, gây sút ăn uống kém lại không phải là nguyên nhân chính khiến người bệnh đi khám bệnh. Tỉ lệ trên cũng giống với kết quả nghiên cứu của Nguyễn Thành Khiêm.

\section{KẾT LUÂ̂N}

- U GIST và u lympho ác tính chiểm tỉ lệ cao nhất tương ứng với $70,6 \%$ và $26 \%$, tổn thương hiếm gặp khác bao gồm u mõ ác tính $(1,3 \%)$, u cơ trớn ác tính và hắc tố ác tính $(0,9 \%)$, u mach máu ác tính và u cơ vân ác tính có tỉ lệ thấp nhất là $0,2 \%$, không có ca nào là u tế bào hạt, u cuộn mach, u Kaposi hay u tế bào sáng.

- Vị trí tổn thương: da dày và ruột non là 2 vị trí thường gặp nhất tại ÔTH, cụ thể: dạ dày $49,6 \%$, tiếp đến là hỗng tràng $(17,2 \%)$, hồi tràng $(7,7 \%)$, tá tràng $(6,8 \%)$, ít gặp hơn theo thứ tự: hậu môn trực tràng $(5,9 \%)$, đại tràng phải $(3,8 \%)$, manh tràng $(3,4 \%)$, đại tràng trái $(2 \%)$, thực quản $(0,9)$ và đại tràng ngang là $0,2 \%$.

- Tỉ lệ các loại u tại các vị trí ÔTH: u GIST gặp nhiều nhất ở dạ dày $(56,7 \%)$, u lympho lại chủ yếu tại dạ dày $(38,8 \%)$ và ruột non $(27,6 \%)$, u mõ gắp nhiều ở đại tràng $(5 / 7)$, u cơ trớn ở da dày $(3 / 5)$ và ruột non $(2 / 5)$, u hắc tố chủ yếu trực tràng (4/5), 1 ca u cơ vân ở đại tràng tràng, 1 ca u mạch tại trực tràng.

- Đặc điểm lâm sàng: Đau bụng là dấu hiệu thường gặp nhất $70 \%$, triệu chứng ung thư là triệu chứng thường gặp của u lympho, thiếu máu hay gặp u GIST và lympho, chủ yếu tiêu hóa cao tại dạ dày, tá tràng, hông tràng, tắc ruột và bán tẳc ruột hay gặp tại ruột non và manh tràng. VFM thường do thủng hoặc hoại tử ruột, chủ yếu ở ruột non, với u lympho và u GIST.

\section{TÀI LIỆ THAM KHẢO}

1. I. D. Nagtegaal et al (2020), "The $2019 \mathrm{WHO}$ classification of tumours of the digestive system", Histopathology, 76(2), p. 182-188.

2. Fred T. Bosman et al (2010), "WHO Classification of Tumours of the Digestive System", 4th ed. World health organization classification of tumours, ed. Fred T. Bosman, Elaine S. Jaffe, Sunil R. Lakhani, \& Hiroko OhgakiIARC, Lyon.

3. Chandrajit P. Raut et al (2017), "Soft Tissue Sarcoma of the Abdomen and Thoracic Visceral Organs", AJCC Cancer Staging Manual 8th Edition, p. 517-521.

4. Pham Gia Anh (2008), "Nghiên cứu đăc điểm giải phẩu bệnh lý và kết quả điều trị phẩu thuật ung thư ống tiêu hóa không thuộc biểu mô tại bệnh viện Việt Đức", Luận văn tốt nghiệp nội trú, Đại học y Hà Nội, Hà Nội.

5. Abeer Ibrahim, Ali Zedan, Alia M. A. Attia (2015), "Localised gastrointestinal diffuse large B cell lymphomas; Does surgical approach still exist?", Forum of Clinical Oncology, 6(1).

6. Ming-Chih Chang, Sung-Hsin Kuo (2017), "Primary Gastric Lymphoma", J Gastroenterol, 3(1).

7. Nguyễn Ngọc Hừng (2002), "Nghiên cứu đặc điểm lâm sàng, cận lâm sàng và điều trị phẩu thuật u dạ dày có niguồn gốc không từ biểu mô tại bênh viện Việt Đức (giai đoạn 1995-2002)", Luận vắn tốt nghiệp nội trú, Đại học Y Hà Nội, Ha Nội

8. Nguyễn Thành Khiêm (2011), "Đặc điểm lâm sàng, cận lâm sàng của u lympho nguyên phát ống tiêu hóa được phẩu thuật tại bệnh viên Việt Đức", Luận văn tốt nghiệp nôi trú, Đại học y Hà Nội, Hà Nộí

\section{THỰC TRẠNG HOẠT ĐộNG BÁO CÁO PHẢN ỨNG CÓ HẠI CỦA THUỐC TẠI BÊ̂NH VIÊ̂N BACH MAI GIAI ĐOÂN 2013 - 2019}

Trần Lê Vương Đại ${ }^{1}$, Trần Ngân Hà², Bùi Thị Ngọc Thực ${ }^{1}$, Nguyễn Thu Minh ${ }^{1}$, Cẩn Tuyết $\mathrm{Nga}^{1}$, Trần Nhân Thắng ${ }^{1}$, Nguyễn Hoàng Anh ${ }^{1,2}$.

\section{TÓM TẮT}

Mục tiêu: Mô tả thực trạng báo cáo phản ứng có hại của thuốc (ADR) tại Bệnh viện Bạch Mai giai đoạn 2013 - 2019. Đối tượng và phương pháp: Mô tả,

${ }^{1}$ Đơn vị Dược lâm sàng - Thông tin thuốc, Khoa Dược, Bênh viên Bach Mai

'Trung tâm Quốc gia về thông tin thuốc và theo dôi phản úng có hại của thuốc, Trường Đại hoc Dược Hà Nội

Chịu trách nhiệm chính: Trần Lê Vương Đại

Email: drvuongdai@gmail.com

Ngày nhân bài: 17.11.2020

Ngày phản biên khoa hoc: 6.01.2021

Ngày duyệt bài: 18.01.2021 cắt ngang trên toàn bô dữ liêu báo cáo ADR được ghi nhận tại bệnh viện và lưu trữ tại Trung tâm DI \& ADR Quốc Gia trong giai đoạn 2013-2019. Kết quả: Tổng số 2.102 báo cáo ADR đã được ghi nhân trong thời gian khảo sát. Số lượng báo cáo ADR của toàn bệnh viện có $x u$ hướng giảm qua các năm $(a=-0,03)$ nhưng chưa đạt mức có ý nghĩa thống kê $(p=0,587)$. Trong khi đó, số lướng báo cáo ADR tự nguyên có xu hướng tăng $(a=0,013)$, nhưng cũng ở mức chưa có ý nghĩa thống kê $(p=0,656)$. Tỷ lê báo cáo ADR/1000 bênh nhân là 2,13. Bác sỹ là đối tượng chính tham gia báo cáo $(58 \%)$, trong khi dược sĩ chỉ chiếm $20,3 \%$ và tăng theo các chương trình giám sát tích cực. Tỷ lệ báo cáo có chất lượng tốt là $62 \%$ và điểm trung bình chất lượng báo cáo là 0,79 . Kháng sinh nhóm beta-lactam 